DOI: http://doi.org/10.21698/simi.2018.fp53

\title{
THE REMOVAL OF NITRATE FROM DRINKING WATER, NATURAL WATER BY ION EXCHANGE USING ION EXCHANGE RESIN, PUROLITE A520E AND A500
}

Nicoleta Vasilache, Liliana Cruceru, Jana Petre, Laura Florentina Chiriac, Iuliana Claudia Paun, Marcela Niculescu, Florinela Pirvu, Giovanina Lupu

National Research and Development Institute for Industrial Ecology-ECOIND, 71-73 Drumul Podu Dambovitei, district 6, 060652, Bucharest, zegreanicoleta@yahoo.com, Romania

\begin{abstract}
Water pollution nitrates contamination of drinking water sources is a global environmental problem causing eutrophication of receiving surface waters, higher levels of nitrates being toxic for infants. Efficient removal of different levels of nitrates in ground water and surface water by using two types of ion exchange resin, A520E and A500 Purolite, was experimentally studied in a fixed bed adsorption column in laboratory scale. Adsorption kinetics was well described by the Langmuir and Freundlich isotherm models for an amount of $2 \mathrm{~g}$ resin and concentrations between 10.18 to $66.8 \mathrm{mg} \mathrm{NO}{ }^{-} \mathrm{L}^{-1}$. The maximum nitrate removal rate in the real water used in this study was $87.2 \%$ for the Purolite A500 resin and $91.6 \%$ for the Purolite A520E resin, indicating a higher efficiency of the A520E resin.
\end{abstract}

Keywords: ion exchange, kinetic adsorption, nitrate removal, Purolite A520, Purolite A500

\section{Introduction}

Contamination with nitrates in groundwater and surface water is an important problem for the whole world. Although nitrates are found in most natural waters at moderate concentrations, elevated levels in groundwater stem mainly from human and animal waste as well as excessive use of chemical fertilizers. Other sources of nitrates are uncontrolled discharges of municipal and industrial wastewater into natural receptors, the execution of septic tanks. Nitrate was involved in methemoglobinemia, especially in children less than six months of age. Symptoms include unusual blue gray skin, irritability, drowsiness and lethargy at higher levels. Nitrates are an essential nutrient for plant growth and micro-organisms. The high concentration of nitrates in water can cause eutrophication, which is a serious environmental problem as it can lead to the abundant aquatic plants, algae growth, have harmful effects on fish and other aquatic life and disturb the ecological balance of present organisms in water.

Due to these adverse effects of nitrates, the World Health Organization has declared nitrate as a regulated water pollutant, and it is necessary to reduce the concentration before it is used for drinking. A requirement for the nitrate removal process is to produce drinking water that meets the standard quality defined by the European Economic Community in Directive 98/83/CE. This Directive limits nitrates to a maximum admissible concentration (MAC) of $50 \mathrm{mg} \mathrm{NO}_{3}^{-} \mathrm{L}^{-1}$.

Techniques available to remove nitrates from water sources that can be treated for drinking purposes have been investigated. Among other techniques such as catalytic 


\section{INTERNATIONAL SYMPOSIUM "THE ENVIRONMENT AND THE INDUSTRY", SIMI 2018, PROCEEDINGS BOOK}

reduction, reverse osmosis, electrodialysis, coagulation and flocculation, the ion exchange process seems to be best suited for small suppliers of nitrate contaminated water due to its simplicity, efficiency, selectivity, recovery and relatively low costs. A variety of adsorbents have been used for the denitrification of drinking water. Strong anionic microporous resins have the best selectivity for nitrates. A variety of anion exchange resins have been used to selectively remove nitrate, such as Purolite A520E, Purolite A100. The selectivity in the adsorption of the nitrate with these resins in the presence of other anions varies depending on the length of the carbon chain of the functional group in the resin. The longer the carbon chain of the functional group in the resin, the selectivity of the nitrate adsorption is higher, becoming more hydrophobic. The resin becomes more selective in the anions, such as nitrate with lower hydration energies. The Purolite A520E resin with triethanolamine functional group showed that the selectivity of anion adsorption follows the order of $\mathrm{NO}_{3}>\mathrm{Cl}^{-}>\mathrm{SO}_{4}{ }^{2-}$ which is the inverse order of hydration energies. Although the A500 resin has characteristics similar to the A520E resin, the effectiveness of the retention of nitrate ions is lower (Bulgariu 2010, Samatya 2006). This study was aimed to investigate the nitrates removal efficiency from ground water and surface water using two selective ion exchange Purolite A520E and A500 resins in fixed bed columns. The objective of this study was divided into two parts: 1) the kinetic study of the nitrate adsorption from two water samples with $\mathrm{NO}_{3}$ - ion concentrations exceed values using the two resins and 2) thermodynamic study.

\section{Materials and methods}

\section{Materials}

The ion exchange resin

Two ion-exchange resin, Purolite A520E and A500 were supplied from Purolite Romania and used as adsorbents. Purolite A520E is a strongly basic anion exchange resin whose structure is composed of polypro polystyrene with divinylbenzene crosslinked, with a triethylamine functional group, specially designed to remove nitrates from drinking water. Microporous matrix and particular functionality of the ion exchange group gives the ideal selectivity of nitrates from Purolite A520E, making this particularly suitable resin for nitrate removal even when moderate sulfate concentrations are higher. Therefore, this resin provides superior performance in the nitrate removal applications compared to other standard ion exchange resins (Modrogan 2010, 2013).

Purolite A500 is also a strong basic anion exchanger with microporous structure of the styrene-divinylbenzene with a trimethylamine functional group designed to fulvic and humic acids removal and tannins from the effluents with higher selectivity for the organic load. Table 1 shows the physical-chemical characteristics of the two resins. 


\section{INTERNATIONAL SYMPOSIUM "THE ENVIRONMENT AND THE INDUSTRY", SIMI 2018, PROCEEDINGS BOOK}

Table 1. The physical - chemical properties of resins Purolite A520E and A500

\begin{tabular}{|c|c|c|}
\hline PARAMETER & A520E & A500 \\
\hline Polymeric structure & $\begin{array}{l}\text { Polystyrene crosslinked } \\
\text { with divinylbenzene } \\
\text { polypropylene }\end{array}$ & $\begin{array}{l}\text { Polystyrene crosslinked } \\
\text { with divinylbenzene } \\
\text { polypropylene }\end{array}$ \\
\hline Aspect & Spherical yellowish & Opaque, white spherical \\
\hline Functional group & $\begin{array}{l}\text { Type I quaternary } \\
\text { amine - } \mathrm{N}\left(\mathrm{C}_{2} \mathrm{H}_{5}\right)_{3}\end{array}$ & $\begin{array}{l}\text { Type I quaternary } \\
\text { amine } \mathrm{N}\left(\mathrm{CH}_{3}\right)_{3}\end{array}$ \\
\hline Ionic form & $\mathrm{Cl}^{-}$ & $\mathrm{Cl}^{-}$ \\
\hline Total capacity [equiv $\mathrm{L}^{-1}$ ] & 0.9 & 1.15 \\
\hline Particle size $[\mu \mathrm{m}]$ & $300-1200$ & $800-1600$ \\
\hline Specific gravity $\left[\mathrm{g} \cdot \mathrm{ml}^{-1}\right]$ & 1.07 & 1.08 \\
\hline Moisture [\%] & $50-56$ & $53-58$ \\
\hline Temperature range $\left[{ }^{\circ} \mathrm{C}\right]$ & $\max .100$ & $\max .140$ \\
\hline $\mathrm{pH}$ range & $0-14$ & $0-11$ \\
\hline
\end{tabular}

\section{Samples}

The investigated samples were from Tulcea County, Babadag and of the Olt county areas groundwaters, nitrate concentrations exceeding permissible limit $55.1 \div 66.8 \mathrm{mg} \cdot \mathrm{L}^{1}$. Surface water samples were colected from the upstream and downstream Corbul Ucei River, which springs from the Făgăraș Mountains and flows into the Olt River, having concentrations between 10.18 and $11.86 \mathrm{mg} \mathrm{NO}_{3}{ }^{-} \mathrm{L}^{-}$ ${ }^{1}$. Drinking water samples were taken from an area in the vicinity of a leguminous seed-producing farms with concentrations of $14.45 \mathrm{mg} \mathrm{NO}_{3}{ }^{-} \mathrm{L}^{-1}$ to $36.39 \mathrm{mg} \mathrm{NO}_{3}{ }^{-} \mathrm{L}^{-}$ 1 .

Table 2. Characteristics of the real waters used in this study

\begin{tabular}{|c|c|c|c|c|c|c|c|c|c|c|}
\hline Parameter & $P 1$ & P2 & $P 3$ & P4 & P5 & P6 & P7 & P8 & P9 & $P 10$ \\
\hline $\begin{array}{c}\mathrm{NO}_{3}{ }^{-}\left[\mathrm{mg}^{-} \mathrm{L}^{-}\right. \\
-\end{array}$ & 10.19 & 11.86 & 14.45 & 18.52 & 22.8 & 23.86 & 36.39 & 52.84 & 55.1 & 66.8 \\
\hline $\begin{array}{c}\mathrm{SO}_{4}{ }^{2-}\left[\mathrm{m}_{1}\right. \\
\mathrm{mg} \mathrm{L}^{-}\end{array}$ & - & - & - & - & - & - & - & - & 18.3 & 48.6 \\
\hline $\begin{array}{c}\text { Turbidity } \\
\text { [NTU] }\end{array}$ & - & - & - & - & - & - & - & - & 0.38 & 1.09 \\
\hline$p H$ & - & - & - & - & - & - & - & - & 7.2 & 7.5 \\
\hline
\end{tabular}

Nitrate concentrations analyzes were performed with UV/Vis spectrophotometer Perkin-Elmer Lambda 25.

Column tests were performed with two lab scale glass columns having an inner diameter of $1.3 \mathrm{~cm}$ and $25 \mathrm{~cm}$ height, fixed resin bed with a $2.5 \mathrm{~cm}$ height. (Figure $1)$.

(a)

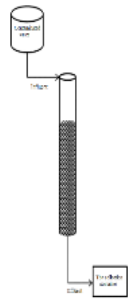

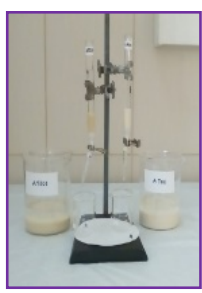

(b)

Figure 1. Anion exchange column, schematically (a) and real (b), on a laboratory scale 


\section{INTERNATIONAL SYMPOSIUM "THE ENVIRONMENT AND THE INDUSTRY", SIMI 2018, PROCEEDINGS BOOK}

Column adsorption experiment was performed with real water sample with $66.8 \mathrm{mg}$ $\mathrm{NO}_{3}{ }^{-} \mathrm{L}^{-1}$ concentration. Progress curves were obtained by collecting the fractions of the effluent in the beakers.

Methods of Analysis

Determination of nitrate was carried out according to SR ISO 7890-3 on water quality by salicylic acid spectrometric method.

Kinetic study of adsorption

In order to study the nitrate adsorption by time, they were used two water samples with high nitrate concentration, P9 (55.1 $\left.\mathrm{mg} \mathrm{NO}_{3} \cdot \mathrm{L}^{-1}\right)$ and P10 (66.8 $\left.\mathrm{mg} \mathrm{NO}_{3}^{-} \cdot \mathrm{L}^{-1}\right)$. The Purolite A520E and A500 resins were hydrated with distilled water for 24 hours at $25^{\circ} \mathrm{C}$ and so maintained throughout the study. Adsorption studies were carried out in static pots in the open, under magnetic stirring, at room temperature $\left(25 \pm 2{ }^{\circ} \mathrm{C}\right)$. 0.2 grams resin quantities were contacted with $10 \mathrm{ml}$ of the sample. Each container was further stirred with a magnetic stirrer at $120 \mathrm{rot} / \mathrm{min}$ at various times $1,3,5,10$, 20, 30 and 60 minutes. After stirring, the solid was separated from liquid phase filtration and the nitrate concentration in the filtrate was analyzed spectrophotometrically at $\lambda=415 \mathrm{~nm}$ compared to the control solution.

Thermodynamic study of adsorption of nitrate on the two resins Purolite

An amount of $1 \mathrm{~g}$ of resin was contacted with $50 \mathrm{ml}$ water samples with various concentrations of nitrate. Allow to stand for 24 hours at room temperature (25 \pm $2{ }^{\circ} \mathrm{C}$ ) considered necessary for reaching the equilibrium ion exchange process. The samples were filtered and nitrate was analyzed. Calculate the nitrate removal efficiency in water samples and analyzing the equilibrium adsorption isotherms justifying the choice of the two resins as selective nitrates retention in groundwater and surface water.

\section{Results and Disscusion}

Study of kinetic adsorption

Experimental data on the kinetics of ion exchange for the anionic microporous morphology Purolite A520E and A500 samples, are shown in Figure 2, in the form of full kinetic curves as adsorbed $\mathrm{NO}_{3}{ }^{-}$amount variation in time. Kinetic curves reveal similar to the high-speed stage ion exchange process of onset and slowing the rate of ion exchange is correlated with $\mathrm{NO}_{3}{ }^{-}$concentration in the solution decrease and the progressive approximation of the steady state system. Figure 3 shows the time variation of the rate of ion exchange A520E, and A500 resins using two water samples with various nitrates concentrations $\left(55,1 \mathrm{mg} \cdot \mathrm{L}^{-1}\right.$ and $\left.66.8 \mathrm{mg} \cdot \mathrm{L}^{-1}\right)$. The rate of ion exchange depends on the size and shape of the ion exchanger particles. The ion exchange reaction is carried out at the interface and, as a rule, it is considered that its speed is much higher than the diffusion processes speed in the liquid phase, so the interface does not introduce resistance to mass transfer. The A520E resin contains smaller size particles than A500, so their specific surface is higher. At high nitrate concentrations the ion exchange speed is higher due to a better mass transfer. From the variation rate of ion exchange in time graph is observed that the rate decreases rapidly during the first 5 minutes, a part of nitrate ions are charged on the surface of the resin particles and then slowly decreases to 30 minutes which was maintained at equilibrium due to the fastening of nitrate. 

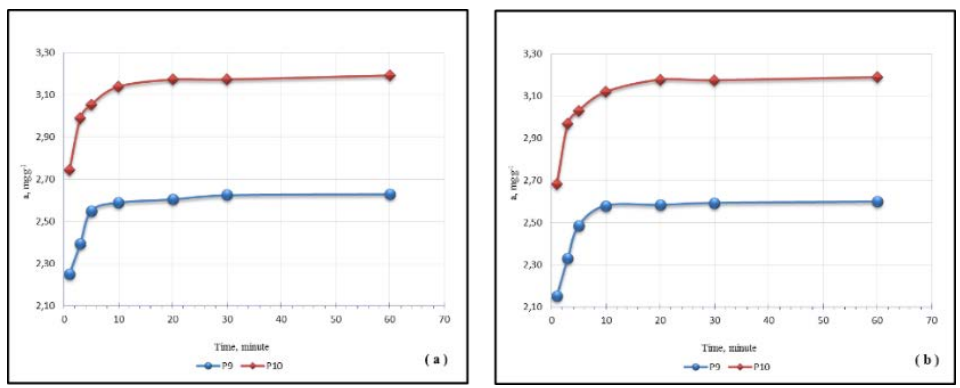

Figure 2. The variation in time of adsorption capacity of nitrates with A520E (a) and A500 (b) resin using two different concentrations $\left(\mathrm{T}=25^{\circ} \mathrm{C} ; \mathrm{pH}=7.2 / 7.5\right)$
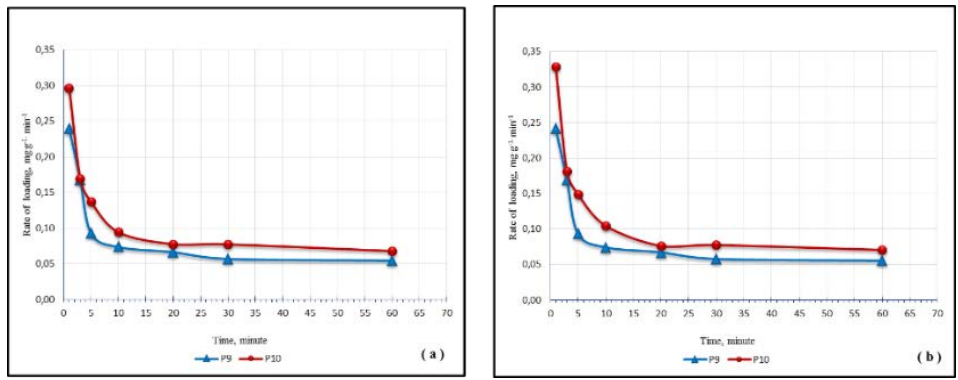

Figure 3. The variation rate of loading in time of A520E (a) and A500 (b) resin (T = $\left.25^{\circ} \mathrm{C}, \mathrm{pH} 7.2 / 7.5\right)$
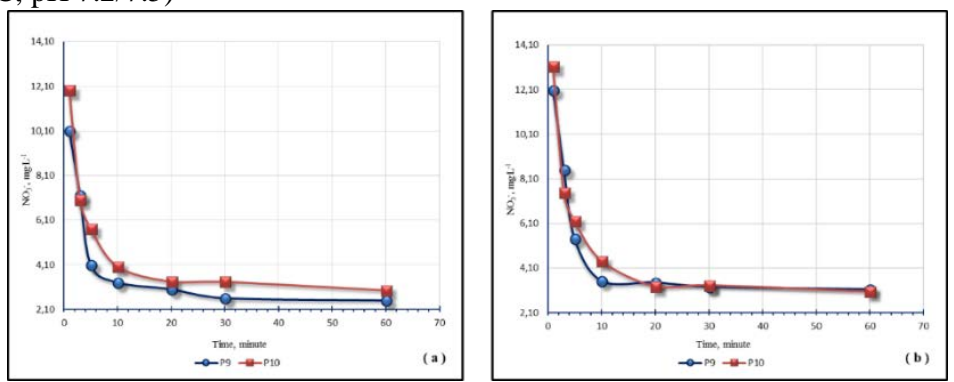

Figure 4. The effect of contact time of A 520E (a) and A500 (b) with two different nitrates concentrations $\left(\mathrm{T}=25^{\circ} \mathrm{C} ; \mathrm{pH}=7.2 / 7.5\right)$ 


\section{INTERNATIONAL SYMPOSIUM "THE ENVIRONMENT AND THE INDUSTRY", SIMI 2018, PROCEEDINGS BOOK}

When using the anionite A520E after 60 minutes of contacting, the nitrate concentration decreased from $55.1 \mathrm{mg} \cdot \mathrm{L}^{-1}$ to $2.06 \mathrm{mg} \cdot \mathrm{L}^{-1}$ (P9) and from $66.8 \mathrm{mg} \cdot \mathrm{L}^{-1}$ to $3.19 \mathrm{mg} \cdot \mathrm{L}^{-1}$ (P10). In the case of using A500 anionite, nitrate concentration decreases from $55.1 \mathrm{mg} \cdot \mathrm{L}^{-1}$ to $2.60 \mathrm{mg} \cdot \mathrm{L}^{-1}$ (P9) and from $66.8 \mathrm{mg} \cdot \mathrm{L}^{-1} 3.05 \mathrm{mg} \cdot \mathrm{L}^{-1}$ (P10).

Figure 4 shows the load variation of the A520E (a) and A500 (b) resins in time. Relatively similar kinetics ion exchange process proved to be a probability due to its similar morphology, and that the ion exchange process is controlled by internal diffusion. In the first 10 minutes nitrate retention was rapid, reaching a maximum at 30 minutes, followed by maintaining toward equilibrium. It was found that 30 minutes is sufficient for nitrate ions retention on both resins. The loading capacity given by the amount of retained nitrate per unit mass of resin [mg. $\mathrm{g}^{-1}$ ] on equilibrium, was higher on the A520E resin, in the range $2.25-2.74 \mathrm{mg} \cdot \mathrm{g}^{-1}$, to A500 resin which was situated between 2.15 and $2.68 \mathrm{mg}^{-1}$.

The effect of contact time is a parameter that shows the efficiency of ion exchange process.

The amount retained nitrate on Purolite resins was calculated using the equation:

$$
a=\frac{(c 0-c t) V}{\mathrm{~m}}
$$

The removal efficiency of nitrate ions from an aqueous solution on the A520E resin was calculated using formula:

$$
R_{v} \%=\frac{C D-c t}{c 0} 100
$$

where: a - is the adsorption capacity of resin $\left(\mathrm{mg}^{-1} \mathrm{~g}^{-1}\right)$, at equilibrium; $\mathrm{C}_{0}$ - initial nitrates concentration in different types of waters $\left(\mathrm{mgNO}_{3}{ }^{-} / \mathrm{L}\right) ; \mathrm{C}_{t}-$ nitrate concentration at time $\mathrm{t}$; $\mathrm{V}$ - solution volume which was contacted the resin $(10 \mathrm{ml})$; $\mathrm{m}$ - mass of the resin ( $0.2 \mathrm{~g})$.

A kinetic study was carried out for the prediction of adsorption rate constants, equilibrium adsorption capacity and adsorption mechanism. The capability of pseudo-first and second order kinetic models were examined in this study at two different initial concentration of nitrate at constant temperature of $25^{\circ} \mathrm{C}$ (Nujic 2017, Nur 2014).

The linear form of pseudo first-order model is generally expressed as follows:

$$
\ln \left(a_{e q}-a_{t}\right)=\ln \left(a_{e q}\right)-k_{1} t
$$

where: $\mathrm{a}_{\text {eq }}$ and $\mathrm{a}_{\mathrm{t}}$ are the adsorption capacity of nitrate per unit weight of resin at equilibrium and at time $\mathrm{t}(\mathrm{min})$, respectively $\left(\mathrm{mg}^{-1} \mathrm{~g}^{-1}\right.$ ), and $\mathrm{k}_{1}$ is the pseudo firstorder rate constant $\left(\mathrm{min}^{-1}\right)$. $\mathrm{k}_{1}$ and aeq values were determined from the slope.

The linear form of pseudo second-order model is expressed as follows:

$$
\frac{1}{a_{t}}=\frac{1}{k_{2} a_{e q}{ }^{2}}+\frac{1}{a_{e q}}
$$




\section{INTERNATIONAL SYMPOSIUM "THE ENVIRONMENT AND THE INDUSTRY", SIMI 2018, PROCEEDINGS BOOK}

Ion exchange rate was calculated using experimental models of the adsorption pseudo-first order and pseudo-second order kinetics.

Ion exchange rate was calculated using experimental models of the adsorption pseudo-first order and pseudo-second order kinetics (Simonin 2016). These models were used to fit discontinuous ion exchange process. The values of the correlation coefficients calculated with can be found in Table 3.

Table 3. The parameters of the two kinetic adsorption models

\begin{tabular}{c|ccccccc}
\hline & & \multicolumn{3}{c}{ Pseudo first - order } & \multicolumn{3}{c}{ Pseudo second - order } \\
\cline { 2 - 8 } & & $\begin{array}{c}\mathrm{a}_{\mathrm{eq}} \\
{\left[\mathrm{mg}^{1}\right]}\end{array}$ & $\begin{array}{c}\mathrm{k}_{1} \\
{\left[\mathrm{~min}^{-1}\right]}\end{array}$ & $\mathrm{R}^{2}$ & $\begin{array}{c}\mathrm{a}_{\mathrm{eq}} \\
{\left[\mathrm{mg}^{-1}\right]}\end{array}$ & $\begin{array}{c}\mathrm{k}_{2} \\
{\left[\mathrm{~min}^{-1}\right]}\end{array}$ & $\mathrm{R}^{2}$ \\
\hline \multirow{2}{*}{ P9 } & A520E & 2.63 & 0.00187 & 0.8199 & 2.63 & 0.00129 & 0.8298 \\
& A500 & 2.60 & 0.00200 & 0.8128 & 2.60 & 0.00168 & 0.8374 \\
& A520E & 3.18 & 0.00160 & 0.8889 & 3.19 & 0.00130 & 0.9070 \\
& A500 & 3.19 & 0.00170 & 0.8903 & 3.19 & 0.00160 & 0.9112 \\
\hline
\end{tabular}

The values of the correlation coefficient suggest that the pseudo - the second order model is most suitable to describe the nitrates retention in the water samples on the A520E and A500 resins, so that the ion exchange process is limited only by the availability of nitrate ions and functional groups on the resin surface.

The efficiency of nitrate removal from water samples actual influenced by the initial values of nitrate concentration was between 81.7 to $82.16 \%$ for the Purolite A520E resin (a) and 78.1 to $80.31 \%$ for the Purolite A500 resin (b) for a maximum of $95 \%$ in both resins. Experimental results show that the percentage of retention decrease with pollutant concentration increasing.

Thermodynamic study of $\mathrm{NO}_{3}{ }^{-}$retention on the A520E and A500 ion-exchangers Ion exchange is an efficient removal process of $\mathrm{NO}_{3}{ }^{-}$from water. This method is suitable on a wide range of concentrations. Ion exchange processes are influenced by a number of factors of which the most important are the nature of ion exchange group of the anionite macromolecular structure and the specific surface of the ion exchanger; the $\mathrm{pH}$ of the wastewater (Tumuzi 2014); the degree of contamination of the wastewater with different chemical species.

Treatment by ion exchange of $\mathrm{NO}_{3}{ }^{-}$contaminated water can be achieved with various types of anion: strongly basic, medium basic, and weakly basic. As chemisorption occurs, the amount of $\mathrm{NO}_{3}^{-}$linked to ion exchanger rise to its maximum capacity. The ionic form, salt or hydroxyl $\left(\mathrm{Cl}^{-}, \mathrm{SO}_{4}{ }^{2-}, \mathrm{NO}_{3}{ }^{-}\right)$of anion exchangers used is a factor which can promote the preferential adsorption of $\mathrm{NO}_{3}^{-}$. The most commonly used form is as salt, typically of $\mathrm{SO}_{4}{ }^{2-}$ or $\mathrm{Cl}^{-}$. The purpose of this part of the paper is the comparative study of the equilibrium and kinetic ion exchange system: water containing $\mathrm{NO}_{3}{ }^{-}$anion exchanger, where the exchanger was Purolite A520E and Purolite A500. For $\mathrm{NO}_{3}{ }^{-}$water removal, two basic chloride anion form A520E, A500 resin was used. The first one is selective $\mathrm{NO}_{3}{ }^{-}$ion while the second is one non-selective.

The objective of this study was to investigate the kinetic parameters for the nitrates removal from groundwater, surface drilling and drinking water, by two adsorption resin Purolite A520E and A500. 


\section{INTERNATIONAL SYMPOSIUM "THE ENVIRONMENT AND THE INDUSTRY", SIMI 2018, PROCEEDINGS BOOK}

Study of the adsorption process of ion $\mathrm{SO}_{4}{ }^{2-}$

A study of the $\mathrm{SO}_{4}{ }^{2-}$ ion adsorption process has been performed in order to emphasize the influence of the selectivity on the nitrates removal from real water samples by ion exchange. The experiment was based on identical conditions with thermodynamic study of nitrates adsorption with the two types of resins.

The results showed a loading of the resin A520E of $0.33 \mathrm{mg}^{-1} \mathrm{~kg}^{-1} \mathrm{SO}_{4}{ }^{2-}$ compared to $2.5 \mathrm{mg} \mathrm{kg}^{-1} \mathrm{NO}_{3}{ }^{-}$and $\mathrm{A} 500$ resin loading $0.93 \mathrm{mg} \cdot \mathrm{kg}^{-1} \mathrm{SO}_{4}{ }^{2-}$ versus $2.9 \mathrm{mg} \cdot \mathrm{kg}^{-1} \mathrm{NO}_{3}{ }^{-}$

The conclusion of this study is that the A500 resin, which has wick selectivity for $\mathrm{NO}_{3}{ }^{-}$will remove $\mathrm{SO}_{4}{ }^{2-}$ ions, reducing its efficiency.

The experimental data were processed by the two equilibrium isotherm models (Langmuir and Freundlich model) in order to establish the best balance of ion exchange adsorption. The Langmuir isotherm adsorption is based on homogeneous monolayer on the surface. The model assumed that the forces are similar to the forces of adsorption and chemical interactions can be used to estimate the maximum retention capacity (a max), corresponding to saturation of the ion exchange resin surface. According to this theory, once a busy center active molecule or another adsorption can't be held, at which the saturation has been reached (Radu 2012).

The former is expressed as follows:

$$
a_{e q}=a_{\max } \frac{k_{1} C_{s}}{1+k_{L} C_{s}}
$$

where $\mathrm{a}_{\max }\left(\mathrm{mg} \cdot \mathrm{g}^{-1}\right)$ is the theoretical maximum monolayer adsorption capacity at the constant temperature, and $\mathrm{K}_{\mathrm{L}}\left(\mathrm{L} \cdot \mathrm{mg}^{-1}\right)$ is the Langmuir constant related to the energy of adsorption. The value of $\mathrm{R}_{\mathrm{L}}$ indicates the shape of Langmuir isotherm to be either unfavorable $\left(R_{L}>1\right)$, linear $\left(R_{L}=1\right)$, irreversible $\left(R_{L}=0\right)$, or favorable $(0<$ $\mathrm{R}_{\mathrm{L}}<1$ ). Also a smaller $\mathrm{R}_{\mathrm{L}}$ value indicates a highly favourable adsorption.

Freundlich isotherm describes the non-ideal and reversible adsorption, the formation unrestricted relative monolayer molecules on the surface of the adsorbent. The adsorption surface is applied to heterogeneous interactions between the adsorbed molecules. This model considers that high affinity centers are busy first. The Freundlich model is expressed as follows:

$$
a_{e q}=K_{F} C_{\theta}^{1 / n}
$$

where $\mathrm{K}_{\mathrm{F}}\left(\mathrm{L} \mathrm{mg}^{-1}\right)$ and $1 / \mathrm{n}$ are Freundlich constants related to the multilayer adsorption capacity and the surface heterogeneity, respectively.

Table 4. Langmuir and Freundlich constants adsorption isotherms for the adsorption of nitrate corresponding to A520E and A500

\begin{tabular}{c|cccccc}
\hline & \multicolumn{3}{|c}{ Langmuir constant } & \multicolumn{3}{c}{ Freundlich constant } \\
\cline { 2 - 7 } & $\mathrm{a} \max$ & $\mathrm{KL}$ & $\mathrm{R}^{2}$ & $\mathrm{n}$ & $\mathrm{KF}$ & $\mathrm{R}^{2}$ \\
\hline A520 & 2.723 & 0.4234 & 0.9787 & 2.30 & 0.8780 & 0.9207 \\
A500 & 7.914 & 0.0659 & 0.9282 & 1.28 & 0.5457 & 0.9735 \\
\hline
\end{tabular}




\section{INTERNATIONAL SYMPOSIUM "THE ENVIRONMENT AND THE INDUSTRY", SIMI 2018, PROCEEDINGS BOOK}

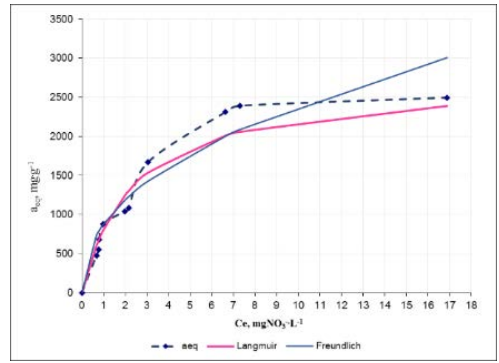

Figure 6. Langmuir-Freundlich overlapping of patterns and experimental data obtained for ion adsorption nitrate in aqueous solution at $25^{\circ} \mathrm{C}$ with the resin, Purolite A520E
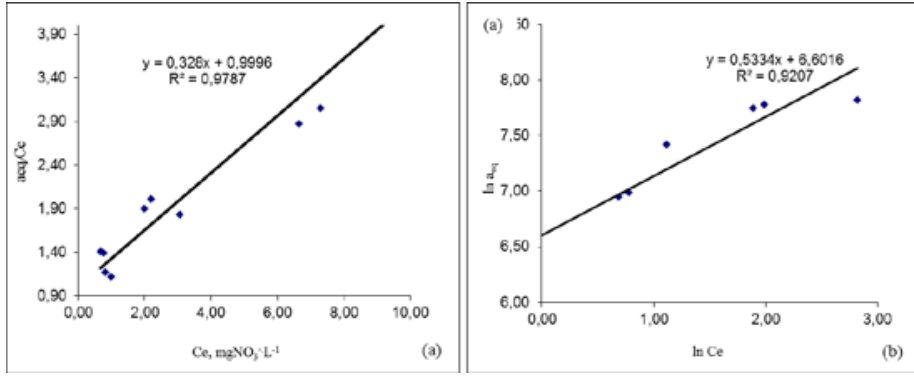

Figure 7. Linearized form of the isotherm: Langmuir (a), Freundlich (b)

In Figure 6 are shown overlapping of Freundlich and Langmuir models with experimental data obtained in the case of nitrates adsorption from water samples by the Purolite A520E resin and their linearized forms: (a) Langmuir, (b) Freundlich, Figure 7. The correlation coefficient $\mathrm{R}^{2}$ in the case of Langmuir model was 0.9787 and 0.9207 in the case of the Freundlich which shows that the adsorption is well described by the Langmuir isotherm.

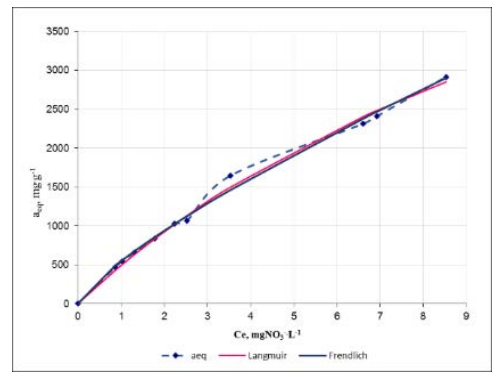

Figure 8. Langmuir-Freundlich overlapping of patterns and experimental data obtained for ion adsorption nitrate in aqueous solution at $25^{\circ} \mathrm{C}$ with the resin, Purolite A500 

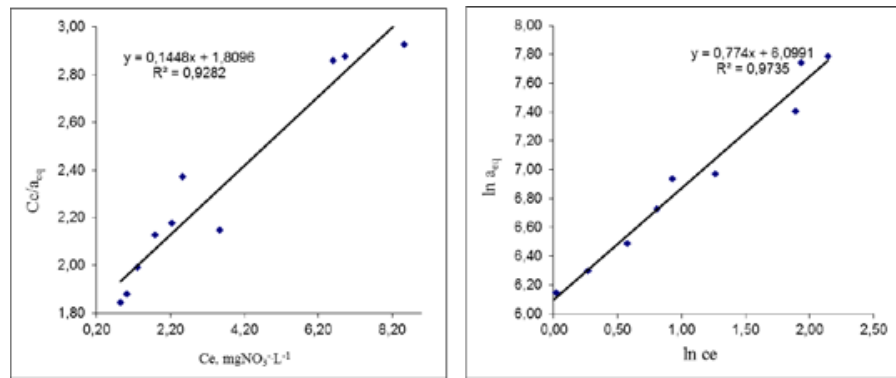

Figure 9. Linearized form of the isotherm: Langmuir (a), Freundlich (b)

In Figure 8 are shown overlapping and Langmuir-Freundlich models with experimental data obtained in the case of nitrates adsorption from water samples to Purolite A500 resin and their linearized forms: (a) Langmuir, (b) Freundlich, Figure 9. The correlation coefficient $\mathrm{R}^{2}$ in the case of Langmuir model was 0.9282 and 0.9735 in the case of the Freundlich adsorption which indicates that aqueous nitrates solutions to Purolite A500 resin is better described by the Freundlich isotherm. Anionite A520E's hold a greater amount of $\mathrm{NO}_{3}{ }^{-}$than anionite $\mathrm{A} 500 . \mathrm{NO}_{3}{ }^{-}$removal efficiency increase to an optimum value above which increase the efficiency of nitrate removal is negligible. At equilibrium, $\mathrm{NO}_{3}{ }^{-}$concentration in the solution increases with increasing initial concentration of $\mathrm{NO}_{3}{ }^{-}$in the solution.

Ion exchange isotherms have similar shapes and indicates close values of $\mathrm{NO}_{3}{ }^{-}$ retention capacities from water under static conditions, although they have total different abilities. At equilibrium, the $\mathrm{NO}_{3}{ }^{-}$amount removed from water is almost identical for the two ion exchangers. The decreased value of the $\mathrm{NO}_{3}{ }^{-}$concentration in water, retention capacity presents high values for both anions which means that it can achieve efficient treatment of water $\mathrm{NO}_{3}{ }^{-}$contaminated through ion exchange.

Due to $1 / \mathrm{n}$ values, the adsorption can be classified as: positive $(0<1 / \mathrm{n}<1)$, bad $(1 / n>1)$, the irreversible $(1 / n=0)$. A value of $1 / n=0.435$ for the A520E resin and $1 / \mathrm{n}=0.779$ for the A500 resin is between 0 and 1 which reflects the adsorption of positive ions of nitrate throughout the range of concentrations subjected to this study, indicating a strong link between ion sorbent nitrate anion exchange resin, Purolite A520E or A500.

The maximum ion exchange efficiency of removing nitrates from actual water used in this study was $87.2 \%$ for Purolite A500 resin and 91.6\% for Purolite A520E resin, which shows a higher efficiency of A520E resin. The maximum efficiency was obtained at lower concentrations of nitrate.

\section{Conclusions}

Ionic equilibrium and kinetic tests were performed for the case of nitrates removal from ground waters, surface waters and drill waters through the two Purolite A520E and A500 resins. The experimental data were processed by methods widely used (isothermal Langmuir and Freundlich) to balance pseudo first and second order kinetic and dynamic study in columns fixed bed of resin. The results have established that the resin A520E has a higher efficiency of ion exchange and higher selectivity than the A500 resin to nitrates removal from different types of water 


\section{INTERNATIONAL SYMPOSIUM "THE ENVIRONMENT AND THE INDUSTRY", SIMI 2018, PROCEEDINGS BOOK}

samples with very high nitrate concentration. The process of $\mathrm{NO}_{3}{ }^{-}$adsorption of the anionic ion exchanger A520E was better represented from Langmuir isotherm while the A500 resin was better represented from Freundlich isotherm. Increased efficiency of the A520E resin was due to the high $\mathrm{NO}_{3}{ }^{-}$ion selectivity, as evidenced by the progress curve of ion exchange. The maximum nitrate removal rate in the real water used in this study was $87.2 \%$ for the Purolite A500 resin and $91.6 \%$ for the Purolite A520E resin, indicating a higher efficiency of the A520E resin.

\section{References}

Bulgariu, L, Lazarus, L, Creţescu I \& Balasanian, I 2010, 'Equilibrium and kinetics study of nitrate removal from water by Purolite A100 resin', Revista de Chimie, vol. 61, no. 11, pp. 1136-1141.

Modrogan, C, Michael, M, Costache, C, Miron, AR \& Orbuleţ, DO 2013, 'Kinetic study of hexavalent chromium removal from wastewaters by ion exchange', Environmental Engineering and Management Journal, vol. 12, no. 5, pp. 929935.

Modrogan, C, Diaconu, E, Orbulet, DO \& Miron, AR 2010, 'Forecasting study for nitrate ion removal using reactive barriers', Revista de Chimie, vol. 61, no. 6, pp. 580-584.

Modrogan, C, Orbulet, OD \& Miron, AR 2014, 'Nitrate Removal from Water using Exchange Resins', Revista de Chimie, vol. 65, no.12, pp. 1502-1506.

Modrogan, C, Miron, AR, Orbulet, OD \& Costache, MC 2010, 'The study of N$\mathrm{NO}_{3}$ restraint on soil', The 8th International Symposium Prospects for the 3rd Millennium Agriculture, Bulletin of University of Agricultural Sciences and Veterinary Medicine Cluj-Napoca, Cluj- Napoca, pp. 129-135.

Nujić, M, Milinkovic, D \& Habuda-Stanić, S 2017, 'Nitrate removal from water by ion exchange', Croatian Journal of Food Science and Technology, vol. 9, no. 2, pp.182-186.

Nur, T, Shim, WGP, Loganathan, S \& Kandasamy, J 2014, 'Nitrate removal using Purolite A520E ion exchange resin: batch and fixed-bed column adsorption modelling', International Journal of Environmental Science and Technology, pp 1311-1320

Radu, C 2012, 'Preparation by ion exchange processes and characterization of functionalized ion exchange resins having complex-forming groups', Summary PhD thesis, University of Bucharest, Chemistry Faculty, Doctoral School of Chemistry. Available from https://www.chimie.unibuc.ro/images/teze_de_doctorat/ 2013-01-18Radu/Radu-ro.pdf. [20 July 2018].

Samatya, S, Kabay, N, Yuksel, U, Arda, M \& Yuksel, M 2006, 'Removal of nitrate from aqueous solution by nitrate selective ion exchange resins', Reactive and Functional Polymers,vol. 66, no.11, pp.1206-1214.

Simonin, JP 2016, 'On the comparison of pseudo-first order and pseudo-second order rate laws in the modeling of adsorption kinetics', Chemical Engineering Journal, pp. 258-261.

Turmuzi, N, Tarigan, ZN, Nadapdap, L \& Batubara, F 2018, 'Effect of pH and complementary ion concentration on nitrate removal using purolite A400 resin impregnated $\mathrm{Cu}$ in batch system', Journal of Nanotechnology, IOP Conference Series : Materials Science and Engineering, vol. 309, pp. 012106. 